\title{
O EDUCADOR E SUA RELAÇÃO COM O PASSADO
}

RESUMO: O texto discute a contribuição dos estudos em História da Educação para a formação dos educadores. Uma situação paradoxal configura-se nessa área de estudos no Brasil, com a expansão vertiginosa da pesquisa e a restrição de seu espaço disciplinar nos cursos de pedagogia. Diante desse quadro, propõe-se uma discussão que tome como perspectiva a relação que o educador, em sua prática profissional, estabelece com o passado, considerando-se que essa questão encontra-se no cerne dos estudos históricos. Para isso, enfocam-se três aspectos dessa relação: $1^{\circ}$.) as sobrevivências do passado no presente; $2^{\circ}$.) as diversas temporalidades que habitam um mesmo tempo; $3^{\circ}$.) as múltiplas formas de subjetivação do tempo.

Palavras-chave: História da Educação; Formação de Professores; Tempo e Temporalidades.

\section{EDUCATORS AND THEIR RELATION WITH THE PAST}

ABSTRACT: This paper discusses the contribution of History and Education studies to the formation of educators. A paradoxical situation exists in this field of study, with a great increase in research in the one hand and on the other hand the restriction of this subject matter in the pedagogy courses in Brazil. Within this context, this paper proposes a debate based on the relation with the past established by educators, in their professional practice, considering this the central issue of historical studies. Three aspects of this relationship are examined: $1^{\text {st }}$ the survival of the past in the current times; $2^{\text {nd }}$ several temporalities coexisting at the same time; $3^{\text {rd }}$ multiple forms of time subjectiveness.

Keywords: History of Education; Formation of Teachers; Time and Temporalities.

*Doutora em História Social pela Universidade de São Paulo (USP); Professora associada da Universidade Federal Fluminense (UFF). E-mail: cmcalves@yahoo.com 
No ano de 2010, foi lançada na França uma publicação intitulada por uma pergunta: "Para que serve a História hoje?"2. Composta por textos curtos, a coletânea reúne 43 historiadores, entre os quais alguns ícones da pesquisa histórica francesa como Arlette Farge, Jacques Le Goff, Michelle Perrot e Philippe Artières, só para citar uns poucos bastante conhecidos no Brasil. O organizador Emmanuel Laurentin (2010) inicia o também curto prefácio com outra pergunta: "Por que esta melancolia?” E discorre sinteticamente sobre o sentimento que toma conta dos historiadores franceses, que perderam seu lugar na mídia e no debate político, uma evidência para qualquer um que tenha estado na França há algumas décadas atrás e retorne hoje.

Tomo aqui o exemplo da França porque, sem dúvida, no ocidente, foi o país em que a pesquisa histórica alcançou maior reconhecimento público e obteve a maior penetração cultural, integrando não só o arcabouço da formação escolar, mas combinando-se com o lazer, o turismo, a educação artística, a vida cultural e o debate político. Não deixa de ser, portanto, um pouco surpreendente que, também lá, os historiadores se vejam suplantados por toda espécie de "especialistas do tempo presente" - expressão usada por Laurentin (2010) - como se o conhecimento sobre o passado tivesse deixado de ser uma das fontes de compreensão do mundo atual.

Sem dúvida, os próprios historiadores recusaram a definição de sua atividade pela exclusiva relação com o passado, na clássica formulação de Marc Bloch (1965) de que a "[...] história é a ciência do homem no tempo". Mas essa percepção dos trânsitos temporais passa por uma conexão fundamental com tempos idos, em geral bastante distanciados do hoje. Para o historiador, o passado continua sendo o seu "bosque encantado", os seus "mares nunca dantes navegados", enfim, seu campo de experimentos e de fascínio.

A história da educação no Brasil, paradoxalmente, apresenta-se como uma área em plena expansão. Os congressos internacionais têm comprovado fartamente como, além de ultrapassarmos numericamente todos os demais países, demonstramos uma capacidade de renovação intensa, com a formação de sucessivas novas gerações de pesquisadores. Apesar de nosso "lugar no mundo" ser desfavorável do ponto de vista da disputa hegemônica no campo científico, temos conquistado algumas posições de destaque, tanto enquanto pesquisadores individuais, como do 
ponto de vista da comunidade, representada pela Sociedade Brasileira de História da Educação.

Não podemos desprezar o crescimento da pós-graduação como um todo, e, em particular, o dos programas da área de Educação como um elemento importante da configuração da história da educação brasileira. Mas não foi esse o fator determinante, já que muitas outras subáreas vivem panoramas bem diversos e até opostos, algumas parecendo ter congelado ou diminuído de tamanho, perdendo terreno para áreas temáticas emergentes. Este Centro de Pesquisa histórica em educação que se inaugura hoje, aqui na UFMG, expressão de um dos polos mais criativos que podemos enumerar no país, é emblemático da capacidade que demonstraram os historiadores da educação brasileiros de agregar e formar para a renovação da pesquisa na área.

Apesar disso, as questões que atravessam o presente e desestabilizam o lugar da história não deixam de repercutir de alguma maneira sobre o nosso subcampo. Talvez o ponto mais evidente seja a perda de espaço nos currículos dos cursos de formação de professores, sob a pressão de conteúdos, temas e problemas que, por vezes, parecem desconsiderar o diálogo com a história, seja presentificando todas as questões, seja reduzindo o passado a uma narrativa simples e ingênua.

Poderíamos, talvez, ficar tranquilos diante do panorama de estímulo à formação inicial e continuada em nível de graduação e pós-graduação de professores para a educação básica, que é um dos traços marcantes da atual política de governo. Nenhum de nós discorda da necessidade de mais e melhor qualificação. Toda política pública, entretanto, fundamenta-se em um conjunto de concepções e mobiliza e desencadeia outras tantas que são postas em marcha na sua implementação e nas formas como a política é recebida e interpretada, num meio tão permeável a novas ideias como é o educacional, embora nem sempre isso se traduza em inovação da prática pedagógica.

Mesmo tendo seu espaço reduzido, a história da educação se mantém, em princípio, dentre o rol das disciplinas requeridas para a formação de educadores. No bojo das mudanças em trânsito, entretanto, fraturas importantes ameaçam a concepção holística que alicerçou a formação de educadores nos conhecimentos oriundos das ciências humanas, e que, no Brasil, historicamente, vinculou a educação a essas ciências. O risco de 
reduzir formação à titulação, na pressa de se produzirem índices animadores, arrasta consigo noções truncadas que podem apontar para uma fratura no campo da pesquisa.

A pior solução para a educação brasileira, neste momento, seria a assimilação da ideia de que a pesquisa acadêmica está distante das necessidades da sala de aula, e de que é possível, senão necessário, produzir-se uma pesquisa que responda rapidamente aos dilemas vividos "no chão da escola", como se esses dilemas fossem resultado de processos momentâneos, superficiais, e pudessem ser tratados com fórmulas metodológicas, como têm proposto diversas Secretarias de Educação, cada vez mais autoritárias no tratamento com os professores, submetidos a pacotes e polícias (vide o que se tem passado com os movimentos grevistas em vários Estados, inclusive em Minas Gerais).

Nesse quadro, os historiadores da educação são chamados a intervir, trazendo a contribuição da sua disciplina. Não há motivo para melancolia, mas não se pode fechar os olhos diante das mutações importantes que enfrentam os educadores em todos os níveis e lugares, e que desafiam a pesquisa educacional como um todo. Para tentarmos contribuir com a reflexão sobre a educação, a partir de uma perspectiva histórica, no entanto, devemos ultrapassar os marcos de um pensamento puramente instrumental. A história da educação é fundamental para o educador, não por ser mais uma disciplina instrumental, mas por auxiliá-lo a se posicionar de maneira completamente diferente diante de problemas que habitam o seu cotidiano e que, muitas vezes, se tornaram invisíveis por tão habituais. A perspectiva histórica reposiciona o educador, não por lhe fornecer programas de ação, mas por lhe permitir descortinar vários nós que obstaculizam as suas ações.

A relação com o passado é um âmbito fundamental da ação educadora, e é nessa relação que é possível identificar a contribuição da pesquisa histórica para o enfrentamento dos problemas detectados na educação em geral, seja na escola ou fora dela. A ilusão mistificadora de que o presente se projeta em direção ao futuro de uma forma quase incontrolável retira dos indivíduos e dos grupos a potência e a responsabilidade de agirem como sujeitos históricos. $\mathrm{Na}$ educação, o discurso da inovação funciona como um motor que, muitas vezes, empurra os educadores numa direção fictícia, um alvo idealizado, infundindo-lhes certezas que não possuem raízes na experiência coletiva e nem parâmetros de avaliação realistas. Os 
resultados cobrados, por outro lado, minimizam o trabalho necessário para sua obtenção, desqualificam as iniciativas e a criatividade dos educadores e silenciam sobre as finalidades maiores da educação como um processo de produção contínua do humano.

A fronteira de desumanidade é sempre muito próxima em qualquer vivência humana e a educação não está fora disso. A modernidade, com todas as suas contradições, representou a busca de parâmetros de humanização que pudessem se apresentar como comuns a toda a humanidade. Se, por um lado, essa busca desaguou em medidas padronizadoras, que justificaram formas ainda mais refinadas de violência contra o próprio ser humano, por outro, construiu horizontes de solidariedade e de direitos válidos para todos. A reflexão educacional é altamente tributária dessa construção moderna, assim como o conhecimento científico e, o que nos interessa em particular, as formulações das ciências humanas. O confronto que temos diante de nós, em um mundo que parece esgotado e, ao mesmo tempo, distante de se ter verdadeiramente humanizado, apresenta-se como o fundo sobre o qual deve se construir essa aproximação dos elos que relacionam o educador e o passado.

A formação de educadores, em qualquer nível, não pode abrir mão de um mergulho na reflexão histórica, como parte do exercício de investigar os problemas educacionais sob novos ângulos. A história da educação não fornecerá um repertório de experiências a serem aplicadas nos dias atuais como soluções possíveis. Mas ela abrirá canais de acesso a uma dimensão que integra a ação educadora de maneira indissociável, que é essa sua relação com o passado. Longe de se constituir numa face visível, unidimensional e de fácil alcance, esse é um campo nublado e cheio de armadilhas.

Nesta fala, escolhemos tratar o tema tomando três aspectos dessa relação:

- as sobrevivências do passado no presente;

- as diversas temporalidades que habitam um mesmo tempo;

- as múltiplas formas de subjetivação do tempo.

$* * * * * * * * * * * * * * *$

Quando falamos em sobrevivências do passado no presente, adentramos ao aspecto mais simples dos três que decidimos tratar aqui. Todos sabemos que da mesma forma como prédios, monumentos, 
documentos sobrevivem e permanecem guardados por longos períodos, também concepções, práticas, valores, preconceitos atravessam os tempos e se manifestam no presente, parecendo por vezes intactos. Esse delicado terreno da memória e de sua preservação é uma das zonas com as quais o educador convive cotidianamente e para as quais precisa de um roteiro no seu percurso.

Daí resulta que quanto mais conhecemos do passado, melhor conhecemos o presente. Embora nunca penetremos no passado, pois em sua inteireza ele nos é inacessível, os elementos que conseguimos reunir, interpretar, relacionar nos dão pistas de como certas experiências se tornaram possíveis. A intimidade que ganhamos com essas experiências de outros tempos vão treinando nosso olhar para o presente. Começamos a observar aspectos que antes passavam despercebidos, ganham sentido gestos que pareciam desconexos, entendemos resistências e tradições.

Todo contato com o passado é de re-conhecimento. Buscar conhecer o passado é, antes de tudo, reconhecer que há várias trilhas de construção que nos antecedem, que muito do que temos e fazemos não seria possível sem o trabalho e as lutas das gerações anteriores. Mas também é reconhecer um rol infindável de atrocidades, é admitir a elasticidade do humano oscilando entre a criação e a morte. Por isso, ver o passado é ver a si mesmo, conhecer o passado é ampliar o conhecimento de si, por meio do contato com o outro. Conhecer o passado é aumentar a sensibilidade para o outro.

O educador precisa dessa ferramenta, porque ele se movimenta num terreno completamente humano. As permanências do passado estão presentes no prédio escolar, na disposição dos móveis, nos materiais didáticos, mas, também, nas atitudes dos seus alunos e suas famílias, nas reações que ele próprio tem em diversas situações, nas dificuldades de aprendizagem, na forma como as crianças manipulam ou destroem o material escolar, nas medidas socioeducativas e nos modos de organização das hierarquias educacionais.

Mas as armadilhas da memória são muitas e variadas. As formas do passado se imiscuem, em geral, de maneira sutil, enquanto se repete infinitamente o discurso da inovação. Quanto mais se recusa a manifestação do passado, mais difícil se torna lidar com o presente.

No caso da escola brasileira, existem memórias subterrâneas com as quais lidam os educadores, que insistentemente se procura "empurrar 
para debaixo do tapete". A questão da escravidão e o fato do racismo, por exemplo, demonstraram-se incontornáveis para pensar a educação brasileira. A escola permanece, na memória coletiva de boa parte da população negra infantil e jovem, como um terreno hostil. $\mathrm{O}$ tratamento discriminatório que sofreram os primeiros grupos negros que chegaram à escola pública republicana, depois de décadas de branqueamento dessa escola, ainda se faz presente no comportamento atual de alunos e professores. Não é suficiente que se estabeleçam provas em vários níveis, que se associem gratificações a resultados, que se criem pressões e obrigações de todo tipo, se não se admitir a dor profunda que atravessa as relações que se estabelecem no espaço escolar. Não para consolidar o tratamento de "coitados", mas para se abrir alguma perspectiva de diálogo.

Outra memória persistente associada a esta primeira é a que naturaliza "a escola pobre para alunos pobres". Com todas as históricas restrições à cidadania que marcam a história brasileira, a desigualdade naturalizou-se em múltiplos padrões de comportamentos e de pensamento. Esses padrões embaçam a noção de público, facilmente capturada pelos interesses privados, e transforma o que seriam direitos em concessões, como se a existência de serviços públicos se inscrevesse na rede de favores que alimenta as formas tradicionais de fazer política no Brasil.

Essa questão atravessa a educação pública brasileira, da pré-escola à universidade, persistindo em discursos que fomentam, no senso comum, a confusão sobre a defesa de uma educação pública de qualidade. No lugar de combater discurso com discurso, o educador necessita compreender a maneira como essa memória persistente solapa sua luta e o seu lugar profissional, esteja ele no sistema público ou privado.

A segunda dimensão, relativa às diferentes temporalidades que se encontram em um mesmo tempo, decorre da primeira. Contrariamente à noção difundida pela física newtoniana de um tempo mensurável, entendido como a sucessão de momentos, como numa série numérica, a percepção histórica aponta, na atualidade, para a convivência e o entrelaçamento das temporalidades em um mesmo tempo.

$\mathrm{Na}$ verdade, o passado nunca se manifesta como uma dimensão completa ou compacta. São muitos passados, por meio de seus traços 
persistentes, que se encontram no presente. O historiador sabe que, cada vez que tenta interpretar questões de um momento que já passou, encontra nelas muitos passados anteriores de diferentes temporalidades. Cada presente passado foi atravessado por essas dimensões. $\mathrm{O}$ momento atual não difere dos anteriores.

Mas por que isso é importante para o educador ou como essas temporalidades atravessam sua atividade? Podemos começar com o papel que a memória desempenha na constituição das identidades. Desconectado das histórias de seu campo profissional, o professor convive com fantasias de tempos dourados, ao mesmo tempo em que se vê mergulhado na desvalorização social do seu trabalho. A história da profissionalização do magistério permite que se compreenda que não há esse passado mítico, pensado dessa forma englobante. Ao contrário, a categoria foi sendo forjada por meio de muitos movimentos que implicaram a liberação do campo religioso, a diferenciação em relação a outros ofícios, a submissão ao poder do Estado, a organização associativa, etc. Compreender como se construíram historicamente as hierarquias que atravessam a profissão, seus elos com tradições advindas de outros campos profissionais, as posições que grupos de professores assumiram em outros tempos pode auxiliar numa percepção identitária mais clara. Pelo menos, pode ajudar a desembaraçar esse emaranhado de fios oriundos de vários tempos que parecem ter amarrado um grande nó que ainda confunde a identidade profissional do magistério. Talvez uma autoimagem mais realista, sem ufanismos e sem derrotismos, pudesse emergir de um conhecimento histórico mais denso a respeito dos diversos movimentos que construíram a profissão, que não podem ser postos numa linha sucessória única, mas que possuem grandes traços que marcaram períodos mais ou menos longos. Ao perceber-se como parte integrante desses movimentos, o educador pode, pelo menos, dar-se conta de um conjunto de representações concorrentes que disputam a sua adesão.

É preciso treinar a sensibilidade para a convivência de fragmentos de muitos tempos na prática educativa. O educador, em qualquer que seja a sua realidade de trabalho, transita entre elementos que, em algum lugar do passado, constituíram-se em inovações pedagógicas. A educação acumula um sem número de invenções nos mais diversos âmbitos: na organização do espaço e do tempo, nos materiais pedagógicos, nos conteúdos e modos de ensino de cada disciplina - elas também, as disciplinas, são invenções -, nas 
hierarquias reais e simbólicas que determinam os papéis a serem assumidos na administração, nos níveis de ensino, nas atividades que preenchem o cotidiano escolar e o ultrapassam, nos valores adotados e rejeitados, nos modos de se pensar os educandos e os educadores...

Essa leitura historicizante entra em rota de colisão com um certo senso comum do discurso pedagógico, sempre em busca do modo mais correto de ensinar, do método mais eficaz, do formato mais adequado. A história chega interrogando essa busca e desestabilizando essas certezas. Ajuda o educador a tomar distância e discernir o velho no que se apresenta como novo. O conhecimento histórico ajuda a desconfiar da eficácia, chamando a atenção para as armadilhas que as muitas temporalidades que se manifestam no presente vão ocultando no caminho das realizações. Nada é tão simples como parece, quando se leva em consideração essas temporalidades.

$* * * * * * * * * * * * * * *$

No caso do terceiro aspecto, o que se refere às múltiplas formas de subjetivação do tempo, ele tem relação direta com o enfrentamento atual entre os tempos construídos e internalizados na relação com a cultura escolar e as novas formas de relação com o tempo, geradas pelas novas tecnologias. A escola hoje parece lenta... Difunde-se a sensação de que o acesso franqueado à informação poderá dispensar a intermediação do educador, enquanto figura de contato direto. Nesse mundo povoado de muitos agentes educativos, atuando na publicidade, na mídia, na televisão, no cinema, nos games, nas redes sociais, que lugar estará reservado para o acesso sistematizado a um certo conjunto de saberes que se organizaram historicamente como disciplinas escolares?

A crítica que empreendemos à ação domesticadora da escola não pode nos conduzir a uma perspectiva ingênua de que seu deslocamento abriria necessariamente um espaço de ação mais livre de constrangimentos, em um mundo no qual outras agências educativas têm se tornado tão poderosas, associadas às novas tecnologias e às novas linguagens que elas estimulam. Por outro lado, a defesa da escola, como instância de democratização do acesso aos códigos de leitura do mundo, no amplo leque de formas de decifração construído pelas ciências e as artes, não pode nos deixar cegos 
diante das enormes mutações, por que passam os processos educativos, e das demandas das novas gerações frente aos desafios do momento presente.

A educação escolarizada, essa construção moderna que nos constituiu como atores do nosso tempo, sem dúvida, passa por constrangimentos importantes. Não só a escola, mas a tríade família-Igreja-escola, que se manteve como o alicerce de introdução das novas gerações aos padrões culturais dos últimos séculos, desestabiliza-se com a força das novas tecnologias. Se, por um lado, podemos observar os traços da forma escolar preservados nos novos veículos transmissores, por outro, novas linguagens e formas de organizar a informação, valores opostos aos que erigiram a disciplinarização dos corpos e mentes na modernidade, uma velocidade e uma abrangência que ultrapassam limites, impõem-se de uma maneira que parecia impensável há meio século.

Mas o que nos interessa enfocar aqui é o impacto dessas transformações sobre as formas de subjetivação do tempo, ou seja, como repercute na educação essa sensação de aceleração temporal. A história da educação tem demonstrado como a escola foi um agente atuante na internalização dos tempos ordenados por lógicas diferenciadas das que regiam tradicionalmente os tempos das famílias. Muito antes das fábricas, os colégios introduziram a repartição dos dias em horários determinados para certas atividades. $\mathrm{O}$ tempo do relógio conjugou-se às culturas escolares como parte de uma série de dispositivos de aculturação propostos para a introdução à cultura escrita.

Essa regulação do tempo construiu um ritmo, uma cadência que alterna atividade e repouso, de forma a oportunizar o recolhimento exigido para o trabalho intelectual. O estudo como fruto da concentração, a descoberta como resultado do aprofundamento, essas noções que ganharam força na educação escolarizada, onde ficarão nesse frenesi de sons e imagens que se precipitam no nosso cotidiano? Há quase duas décadas, Adauto Novaes escreveu que começávamos a nos esquecer de como é " [...] fecundar o silêncio, entendendo silêncio não como ausência de palavra mas como condição de existência da própria palavra, pois é o intervalo entre as palavras - o silêncio - que dá sentido à linguagem" (1992, p. 13). Podemos nos perguntar se a mudez das pessoas de todas as idades diante de aparelhos que tagarelam todo o tempo, por meio de textos, sons e imagens eliminou o lugar desse silêncio de que nos fala o autor. Um 
silêncio aberto aos voos do pensamento e da imaginação. Um silêncio que desacelera o tempo interno, para abrir espaço à reflexão e à criação. Em grande parte, fomos treinados para esse exercício pela educação escolar e todo o aprendizado embutido nos modos de ler e escrever silenciosamente, de organizar o pensamento antes de se expressar, de reunir os argumentos para envolver o nosso interlocutor. Formas de lidar com os tempos sociais que foram sendo introjetadas e constituíram uma sensibilidade particular.

Cabe ao educador interrogar-se sobre o destino desse patrimônio frente ao prodígio tecnológico que nos empurra para o predomínio da fantasia no lugar da imaginação, e do escapismo no lugar do recolhimento. Volto a Adauto Novaes, que traçou um diagnóstico bastante pessimista:

Se uma época se define pelo que ela tolera, pode-se dizer que a nossa é a da desrazão. Enfim, séculos de trabalhos do pensamento e da razão, realizados lentamente, dolorosamente, são desacreditados à velocidade de um carro de corrida: renasce entre nós um movimento em favor do desumano e das superstições (1992, p. 14).

Podemos não ser tão pessimistas, mas algumas preocupações são inevitáveis. E é bom que nos preocupemos. Porque educação é projeto. Educar requer definir escolhas para o futuro. Em cada decisão na sua prática educativa, o educador está implicado num projeto de humanidade. Por isso, não é possível naturalizar as transformações e fechar os olhos para as consequências das novas formas de subjetivação temporal. Entender que isso é parte de uma construção histórica fortalece a aposta de que nenhum processo é irreversível, mesmo que não tenhamos força para revertê-lo de imediato. No mínimo, temos de pensar a respeito de tudo isso.

As novas tecnologias parecem contribuir para a implosão da ideia de um tempo linear e absoluto, mas, por outro lado, introduzem uma experiência temporal marcada pela fragmentação e por uma espécie de distanciamento de si. Apropriadas pelo individualismo e o consumismo galopantes, demonstram-se poderosas na modelagem de comportamentos voltados para a competição ininterrupta, na busca de um prazer que parece inalcançável. Uma busca que explode em violência explícita, que dilacera a intimidade e instaura a guerra permanente atravessando as relações sociais.

Talvez mais do que nunca os educadores precisem da história, não para resgatarmos a ilusão de que as lições do passado ainda seriam úteis, 
noção que nós próprios, historiadores, combatemos. Mas para perceber, sim, o conhecimento do passado como um recurso inesgotável de ferramentas que aguçam nossa percepção do presente e nos ajudam a refletir sobre as escolhas para os projetos de futuro. A história nos auxilia a fugir das certezas fáceis e nos apropriarmos do direito à incerteza, repondo o lugar da ação dos sujeitos, instaurando novas possibilidades de vida e de humanização. Essas novas possibilidades são o centro de qualquer ação educativa. 


\section{REFERÊNCIAS}

BLOCH, M. Introdução à história. Lisboa: Publicações Europa-América, 1965.

LAURENTIN, E. À quoi sert l'bistoire aujüurd'bui? Montrouge: Bayard, 2010.

NOVAES, A. (Org.). Tempo e história. São Paulo: Cia. das Letras; Secretaria Municipal de Cultura, 1992.

\section{NOTAS}

${ }^{1}$ Conferência proferida por ocasião da inauguração do Centro de Pesquisas em História da Educação da FAE/UFMG.

${ }^{2}$ Em francês, o título é À quoi sert l'histoire aujourd'hui?

Recebido: 02/04/2012

Aceito: 10/09/2012

Contato:

Universidade Federal Fluminense Faculdade de Educação

Rua Professor Marcos Valdemar Freitas Reis, s/n, Bloco D., São Domingos, Campus Gragoatá CEP 24210-201

Niterói, RJ

Brasil 